\title{
TITLE: Urban Environment Cues for Health and Well-being in the Elderly
}

\author{
Maria Anna Gardener ${ }^{\mathrm{a}^{*}}$ and Fabiano Lemes de Oliveira ${ }^{\mathrm{a}}$
}

${ }^{a}$ School of Architecture, Faculty of Creative and Cultural Industries, University of Portsmouth, Hampshire, United Kingdom.

\section{CORRESPONDENCE}

Maria Anna (known as Marianna) Gardener ${ }^{a^{*}}$

School of Architecture

University of Portsmouth

Eldon Building

Winston Churchill Avenue

Portsmouth

PO1 2DJ

United Kingdom

E-mail: marianna.gardener@port.ac.uk

Total word count (excluding this page, abstract, references at end of article and two tables) 8,828

Acknowledgement: This original scholarship review was undertaken with the support of a University of Portsmouth scholarship. 


\title{
Urban Environment Cues for Health and Well-being in the Elderly
}

\begin{abstract}
Urban populations are increasing at a rate that challenges existing public health infrastructures, while contemporary literature proliferates in the attempt to identify links between city neighbourhoods and health and well-being. Despite this, there have been few attempts to synthesise research into neighbourhood features perceived by elderly residents to affect their health and well-being. The primary objective of this review is to establish whether and, if so, how the perception of urban environment features acts as health and well-being determinants in an ageing population. Data extracted from 49 eligible articles into five key neighbourhood domains and thematic analysis show that poor health and reduced activity are associated with negatively perceived environments. In addition, urban social cohesion, crime and safety influences activity choices. Higher activity is associated with more compact and varied land-use mix with appealing aesthetics. Isolating individual perceived neighbourhood features as directly associated health determinants among the elderly is complex due to inter-relations and overlap between domains. Identification of perceived environment health and well-being barriers or facilitators by the elderly are under-represented and warrants further investigation. Participatory objective and subjective research will contribute towards a more robust evidence base for public health professionals and policymakers by identifying knowledge gaps.
\end{abstract}

Keywords: Health; Well-being; Elderly; Perception; Urban Environment; Neighbourhood

\section{Introduction}

Provision of healthy city infrastructures that are fit for purpose while catering for increasing older urban populations is an ongoing logistical challenge. The global ageing population is projected to accelerate from $12.3 \%$ in 2015 to $21.5 \%$ in 2050 (United Nations, 2017) when $25 \%$ of the worldwide population is estimated to be over 65 years old (OECD, 2017), placing elderly in developing countries at particularly high risk due to unique challenges and contexts posed by each locale. Recognised positive urban environment determinants of health and well-being are found in an urban fabric incorporating human-scale design that includes green spaces, parks and opportunities for community cohesiveness (Mitchell and Popham, 2008; Maas et al., 2009; de Vries et al., 2013; Tallis et al., 2015; Ward Thompson, Silveirinha de Oliveira, et al., 2016; Lemes de Oliveira, 2017), neighbourhood orderliness (Taylor, Twigg and Mohan, 2015; Ambrey, 2016); and active transport (Frank and Engelke, 2005; Koohsari, Badland and Giles-Corti, 2013; Chang, 2016; de Blasio, 2016; Sallis, Bull, et al., 2016; Lewis, 2017). Despite this evidence there remains a paucity in the literature defining specific features 
of the neighbourhood perceived by older residents to contribute to or moderate their health and wellbeing.

The neighbourhood where people live their day-to-day lives provides complex influences that impact directly upon health and well-being. Socio-economic and health and well-being inequities within cities are the focus of a growing body of contemporary research, demonstrating the impact and legacy of living in a deprived area. This includes reduced lifespan, higher unemployment, lower education levels, and higher levels of anti-social behaviour and crime; together with increased prevalence of chronic disease (Department for Communities and Local Government, 2015; Marmot, 2015; Taylor, Twigg and Mohan, 2015; Nabielek, Hamers and Evers, 2016). In addition to lower socio-economic status and physical inactivity, poor lifestyle choices (Lakerveld et al., 2015; Nabielek, Hamers and Evers, 2016) may result in life-limiting morbidity in an obesogenic environment (Townshend and Lake, 2017).

This article provides a review of the literature to identify, synthesise and classify perceived community characteristics by the elderly. Structured as follows: section two provides the literature context for relationship to place influence on health and well-being and the role that perception plays. Section three explains the methods undertaken to source and select relevant articles for this review. Section four reports on results and identifies perceived place-associated indicators for health and wellbeing and the discussion in section five relates outcomes to the broader context of the literature. Section six makes recommendations for ongoing research to address identified gaps. In this article, the term "urban environment" encompasses all characteristics of physical structures in man-made environments in which we live, work, travel and play and is used interchangeably with the words' neighbourhood and community. The term elderly is applicable to a population aged $\geq 65$ chronologically according to the National Health Service (NHS) in England (NHS England, 2018). In turn, the United Nations and World Health Organization define older people as $\geq 60$ years (Beard, 2014; United Nations, 2017). In this article, the term "elderly" is used interchangeably with the terms older and ageing and includes participants that are $\geq 60$ years of age.

\section{Relationship to Place and Influence on Health and Well-being}

The relationship between the neighbourhood environment and health and well-being has changed over time with increasing urban populations bringing added pressures on public health infrastructures. For example, prior to urbanisation, health problems were restricted to illnesses that included malaria, childbirth complications, predator injury and food availability (Milne, 2017). However, today urban health within and of itself is the product of complex political, environmental, social, cultural and economic variables (Wilkinson and Pickett, 2010; Marmot, 2015; Milne, 2015; Fioramonti, 2017). Milne (2017) argues that the humankind palaeolithic (hunter-gatherer) genome has not changed and 
that to function optimally people need fresh air, fresh food and water; our lungs and digestive systems are not built to cope with urban levels of processed food and pollution.

Physical inactivity on its own is predictive of poor health and well-being and increased prevalence of chronic disease (Blair, 2009; Lee et al., 2012; Booth et al., 2017; Heron et al., 2019). For example, a study of 1.2 million women in the United Kingdom (Floud et al., 2016) showed that coronary heart disease in older women was associated, among other factors, with inactivity. This finding is not restricted to the elderly, as children living in high deprivation areas in New Zealand and lower socioeconomic areas in England showed an increased diagnosis of morbid obesity, which increases cardiometabolic risk factor and early signs of vascular dysfunction (Garnett et al., 2016).

In older elderly populations activity levels diminish due to increasingly limited mobility compounded by the likelihood of associated comorbidity. Ultimately, isolation and reliance upon external support increases. Yet the increasing physiological frailty trajectory may be moderated by the salutogenic role played by an urban and community design that promotes physical activity (Kerr, Rosenberg and Frank, 2012). Encouraging mobility and social interaction access requires proximity to resources such as recreational facilities, transport, and a user-friendly secure walking environment (Levasseur et al., 2016).

The places where people live are predictive for health and well-being, as demonstrated by the index of multiple deprivation in England (Department for Communities and Local Government, 2015). One of the first studies to systematically review people and place examined features of two contrasting socioresidential characteristics and mortality data in a North West, more affluent, and South West, less affluent area of Glasgow to attempt to help explain the differing health profiles by identifying environmental mechanisms that may positively or negatively influence health (Macintyre, Maciver and Sooman, 1993). The study concluded how important it is to find out more information on inherent mechanisms, beyond the numbers produced by statistics, hinting that there is more to it than social class or area of residence that might influence health and inform policy formation (ibid). One of these influencing factors is whether the environment lends itself to being physically active or not.

The nexus effects of increased urbanisation, exposure to air pollution, living in a neighbourhood that is highly deprived and being physically inactive have particular dire consequences for the ageing members of society. Increased urbanisation combined with an escalation in the ageing population and rising social and economic inequality in health (Grant et al., 2017) are on a convergent course with grim economic implications. To short circuit an increasing drain on finances the current dominant public health medical model (Iacobucci, 2018) needs to be turned around to one that promotes health and wellbeing by providing equal access to environments that are salutogenic and prompt well-being. 


\section{Role of Perception}

Perception is a term that defines cognitive processing, integration and interpretation of complex external stimuli encountered in daily life that involves experience and memory, informing pre-existing life experiences (Bell et al., 2001). Therefore, how you locate and situate yourself in place requires your viewpoint and perspective from where you are as a starting point (Rietveld, 2010). In psychological terms there appears to be a preference for urban environments that are perceived to facilitate travel and finding the way along a route; not too open without defining features or too closed in so that the view ahead is obstructed (Bell et al., 2001). This includes not only the objective landscape but also the viewpoint of the observer who co-ordinates with people and things in the landscape, while bringing their own frame of reference and lived experience to the place (van Dijk and Rietveld, 2017).

In an ageing population, a place perceived to be stressful or pleasurable impacts on what Lawton \& Nahemow (1973) and Nahemow \& Lawton (1973) refer to as environmental press, in other words the impact on an individual's competence or adaptability. If the environmental press is negative, the elderly may be pushed beyond their comfort zone and adaptation level and find the situation intolerable and maladaptive behaviour may result. Conversely, if the environmental press is perceived to be positive, positive feelings and adaptive behaviour may occur (Lawton and Nahemow, 1973; Nahemow and Lawton, 1973). Furthermore, aesthetically pleasing environments may affect human experience and behaviour and create a cognitively distinct preference (Kaplan, 1987).

Perception and wayfinding in a neighbourhood require visual image mapping at a starting point. The importance of being able to recognise the environment, otherwise known as legibility in familiar routes, was identified in the seminal work 'The Image of the City' as important considerations for planning (Lynch, 1960). Wayfinding through identifiable landmarks is almost an unconscious automatic process; however, if orientation in a place is lost a level of distress may arise. Psychological distress is known to be related to objective measures of neighbourhood quality, amount of green space, land-use mix, industry and traffic volume (Gong et al., 2016), however, associated subjective environment perception is not commonly correlated with health outcomes in the literature.

\section{Methods}

A rapid evidence review method was undertaken systematically. Although with fewer stages than a systematic review, it has been deemed to provide similar conclusions to systematic reviews (Featherstone et al., 2015; O'Leary et al., 2017) and used to inform public health policy (Smith et al., 2018). Primary empirical research papers, or papers that analysed primary data generated by previous surveys retrospectively, published in peer-reviewed journals, were retrieved from the following databases: Discovery Ebsco host, which returns outputs listed in numerous bibliographic databases, including but not limited to, Scopus; Science Direct; PsycINFO; ERIC; CINAHL; SPORTDiscus; OAPEN Library; SocINDEX and JSTOR. Complementary searches were also run directly in Scopus, 
Medline, Web of Science and Geobase to ensure that relevant articles were not missed. The timeframe for publication date was set between 2010 and 2017 to hone the focus on contemporary additions to the literature. Only English research papers that comprised a cohort of $\geq 20 \%$ older people (participants aged $\geq 60$ years), or, if age of participants was omitted, that reported on research outcomes for older adults were included. Articles were rejected if they did not include participant identified perceived environmental characteristics and associations with health or well-being.

Core keywords and synonyms were used in the searches to ensure that no relevant publications were overlooked. These included the terms "Health" AND "Well-being" OR "Wellbeing” OR "Well Being"; AND "Perception" OR “Attitude" OR "Opinions" OR "Experience" OR "View” OR "Reflection" OR "Beliefs" AND "Urban Environment" OR "Neighborhood" OR "Neighbourhood" AND "Elderly" OR “Aged” OR “Older” OR “Elder” OR “Geriatric” NOT “Children” OR “Adolescents” OR "Youth” OR "Child" OR "Teenager".

The suitability of publications for inclusion was appraised by using an adapted list of questions from two existing quality assessment tools: the National Institute for Health and Care Excellence (NICE) quality appraisal checklists for development of public health guidance and the Critical Appraisals Skills Programme qualitative study research screening questions (NICE, 2013; Critical Appraisal Skills Programme, 2017). A criterion was rated positive when met, negative when not met. Overall quality was calculated by adding the scores and rated high if they had $100 \%$ positive score, medium with a 75 $100 \%$ score and low if less than $75 \%$. After initial selection from reading titles, abstracts and full text records a data extraction table was developed inductively and iteratively in Excel by the authors. Data were synthesised using thematic analysis (Joffe and Yardley, 2004).

\section{Results}

Database searches returned 1,480 publications, of which 1,069 were excluded based on applying inclusive and exclusive criteria. A further 251 were duplicates and 160 publications were eligible for full-text review of which 32 articles were included in the final analysis. An additional 17 articles were sourced through searching reference lists, bringing the total to 49 articles included in the review. Most of the articles (11 of 49) were from the United States, followed by six articles from both Canada and Scotland. Three were from England, Germany, Brazil and Australia and the remaining 14 were from other countries. The authors, year of publication, participant demographics, methods used, study quality score and country of origin are summarised in Table 1. 
Table 1. Authors, Cohort Demographic, Method, Study Quality, Country and Location

\begin{tabular}{|c|c|c|c|c|c|c|}
\hline Authors & Cohort Age & Number & Method & Quality & Country & Location \\
\hline $\begin{array}{l}\text { Adams et al. } \\
2012\end{array}$ & $\geq 66$ & $(\mathrm{n}=728)$ & $\begin{array}{l}\text { Cross sectional } \\
\text { Mixed methods }\end{array}$ & High & $\begin{array}{l}\text { United } \\
\text { States }\end{array}$ & $\begin{array}{l}\text { Baltimore and } \\
\text { Seattle }\end{array}$ \\
\hline $\begin{array}{l}\text { Blay et al. } \\
2015\end{array}$ & $\geq 60$ & $(\mathrm{n}=6963)$ & $\begin{array}{l}\text { Cross sectional } \\
\text { Mixed methods }\end{array}$ & High & Brazil & $\begin{array}{l}\text { Rio Grande do } \\
\text { Sul }\end{array}$ \\
\hline $\begin{array}{l}\text { Bjornsdottir et } \\
\text { al. } 2012\end{array}$ & $\begin{array}{l}\text { Women } \\
72 \text { to } 97\end{array}$ & $(n=10)$ & $\begin{array}{l}\text { Cross-sectional, } \\
\text { qualitative }\end{array}$ & High & Iceland & Akureyri \\
\hline $\begin{array}{l}\text { Brookfield et } \\
\text { al. } 2017\end{array}$ & $\geq 60$ & $(n=22)$ & $\begin{array}{l}\text { Cross sectional, } \\
\text { qualitative }\end{array}$ & Medium & Scotland & Edinburgh \\
\hline $\begin{array}{l}\text { Browne-Yung } \\
\text { et al. } 2016\end{array}$ & $\geq 60(\mathrm{n}=256)$ & $(\mathrm{n}=601)$ & $\begin{array}{l}\text { Cross sectional } \\
\text { Mixed methods }\end{array}$ & Medium & Australia & Adelaide \\
\hline $\begin{array}{l}\text { Chaudhury et } \\
\text { al. } 2016\end{array}$ & $\geq 60$ & $(n=434)$ & $\begin{array}{l}\text { Cross sectional } \\
\text { Mixed methods }\end{array}$ & Medium & $\begin{array}{l}\text { Canada \& } \\
\text { USA }\end{array}$ & $\begin{array}{l}\text { Vancouver } \\
\text { and Portland }\end{array}$ \\
\hline $\begin{array}{l}\text { Chudyk et al. } \\
2015\end{array}$ & $\geq 65$ & $(n=150)$ & $\begin{array}{l}\text { Cross sectional } \\
\text { Mixed methods }\end{array}$ & High & Canada & Vancouver \\
\hline $\begin{array}{l}\text { Day. } \\
2010\end{array}$ & 62 to 90 & $(n=45)$ & $\begin{array}{l}\text { Case study } \\
\text { Qualitative }\end{array}$ & Medium & Scotland & Glasgow \\
\hline $\begin{array}{l}\text { De Donder et } \\
\text { al. } 2013\end{array}$ & $\geq 60$ & $(\mathrm{n}=25,980)$ & $\begin{array}{l}\text { Cross sectional } \\
\text { Mixed methods }\end{array}$ & Medium & Belgium & Flanders \\
\hline $\begin{array}{l}\text { Dong \& } \\
\text { Bergren. } 2017\end{array}$ & $\geq 60$ & $(n=3158)$ & $\begin{array}{l}\text { Cross sectional } \\
\text { Mixed methods }\end{array}$ & Medium & $\begin{array}{l}\text { United } \\
\text { States }\end{array}$ & Chicago \\
\hline $\begin{array}{l}\text { Douma et al. } \\
2017\end{array}$ & $\geq 65$ & $(n=66)$ & $\begin{array}{l}\text { Cross sectional } \\
\text { Qualitative }\end{array}$ & High & $\begin{array}{l}\text { Nether- } \\
\text { lands }\end{array}$ & North Eastern \\
\hline $\begin{array}{l}\text { Eibich et al. } \\
2016\end{array}$ & $\begin{array}{l}\geq 60(\mathrm{n}=993) \\
20-35(\mathrm{n}=312)\end{array}$ & $(\mathrm{n}=1,305)$ & $\begin{array}{l}\text { Cross sectional } \\
\text { Mixed methods }\end{array}$ & Medium & Germany & Berlin \\
\hline $\begin{array}{l}\text { Ferreira et al. } \\
2010\end{array}$ & $\geq 60$ & $(\mathrm{n}=1,611)$ & $\begin{array}{l}\text { Cross sectional } \\
\text { Mixed methods }\end{array}$ & Medium & Brazil & $\begin{array}{l}\text { Belo } \\
\text { Horizonte }\end{array}$ \\
\hline $\begin{array}{l}\text { Gale et al. } \\
2011\end{array}$ & $69-78$ & $(\mathrm{n}=1157)$ & $\begin{array}{l}\text { Cross sectional } \\
\text { Quantitative }\end{array}$ & Medium & England & Hertfordshire \\
\hline $\begin{array}{l}\text { Gao et al. } \\
2017\end{array}$ & $\geq 60$ & $(\mathrm{n}=2719)$ & $\begin{array}{l}\text { Cross sectional } \\
\text { Mixed methods }\end{array}$ & Medium & China & Shanghai \\
\hline $\begin{array}{l}\text { Gardner. } \\
2011\end{array}$ & $\geq 75$ & $(n=6)$ & $\begin{array}{l}\text { Longitudinal } \\
\text { Mixed methods }\end{array}$ & Medium & Canada & Toronto \\
\hline $\begin{array}{l}\text { Gauvin et al. } \\
2012\end{array}$ & $67-84$ & $(\mathrm{n}=521)$ & $\begin{array}{l}\text { Longitudinal } \\
\text { Mixed methods }\end{array}$ & High & Canada & Quebec \\
\hline $\begin{array}{l}\text { Giehl et al. } \\
2012\end{array}$ & $\geq 60$ & $(n=1656)$ & $\begin{array}{l}\text { Cross sectional } \\
\text { Quantitative }\end{array}$ & High & Brazil & Florianopolis \\
\hline $\begin{array}{l}\text { Giraldez-Garcia } \\
\text { et al. } 2013\end{array}$ & $\begin{array}{l}\text { Mean age } \\
72.07 \pm 7.83\end{array}$ & $(\mathrm{n}=1106)$ & $\begin{array}{l}\text { Cross sectional } \\
\text { Quantitative }\end{array}$ & High & Spain & \\
\hline $\begin{array}{l}\text { Hayward et al. } \\
2015\end{array}$ & $\begin{array}{l}21-71 \\
50.6 \pm 12.3\end{array}$ & $(\mathrm{n}=28)$ & $\begin{array}{l}\text { Cross sectional } \\
\text { Qualitative }\end{array}$ & Medium & $\begin{array}{l}\text { United } \\
\text { States }\end{array}$ & $\begin{array}{l}\text { Baltimore, } \\
\text { Maryland }\end{array}$ \\
\hline $\begin{array}{l}\text { Huong et al. } \\
2012\end{array}$ & $\geq 60$ & $(n=90)$ & $\begin{array}{l}\text { Cross sectional } \\
\text { Qualitative }\end{array}$ & Medium & Vietnam & $\begin{array}{l}\text { Urban and } \\
\text { rural }\end{array}$ \\
\hline $\begin{array}{l}\text { Jones et al. } \\
2014\end{array}$ & $\begin{array}{l}\geq 65(\mathrm{n}=1549) \\
\leq 64(\mathrm{n}=6697)\end{array}$ & $(\mathrm{n}=8237)$ & $\begin{array}{l}\text { Cross sectional } \\
\text { Quantitative }\end{array}$ & High & Scotland & Glasgow \\
\hline $\begin{array}{l}\text { Kearns et al. } \\
2015\end{array}$ & $\geq 65(\mathrm{n}=951)$ & $(\mathrm{n}=4,000)$ & $\begin{array}{l}\text { Cross sectional } \\
\text { Quantitative }\end{array}$ & Medium & Scotland & Glasgow \\
\hline $\begin{array}{l}\text { Kent et al. } \\
2017\end{array}$ & $\begin{array}{l}45-64(\mathrm{n}=199) \\
\geq 65(\mathrm{n}=98)\end{array}$ & $(\mathrm{n}=562)$ & $\begin{array}{l}\text { Cross sectional } \\
\text { Mixed methods }\end{array}$ & Medium & Australia & Sydney \\
\hline $\begin{array}{l}\text { Kolbe et al. } \\
2015\end{array}$ & $\begin{array}{l}\text { Mean age } \\
65 \pm 8.5\end{array}$ & $(n=44)$ & $\begin{array}{l}\text { Cross sectional } \\
\text { Mixed methods }\end{array}$ & Medium & $\begin{array}{l}\text { South } \\
\text { Africa }\end{array}$ & Cape Town \\
\hline
\end{tabular}




\begin{tabular}{|c|c|c|c|c|c|c|}
\hline Authors & Cohort Age & Number & Method & Quality & Country & Location \\
\hline $\begin{array}{l}\text { Lo et al. } \\
2017\end{array}$ & $40-91$ & $(\mathrm{n}=118)$ & $\begin{array}{l}\text { Cross sectional } \\
\text { Mixed methods }\end{array}$ & Medium & $\begin{array}{l}\text { United } \\
\text { States }\end{array}$ & Montana \\
\hline $\begin{array}{l}\text { Mahmood et al. } \\
2012\end{array}$ & $\geq 65$ & $(n=66)$ & $\begin{array}{l}\text { Cross sectional } \\
\text { Mixed methods }\end{array}$ & High & Canada & $\begin{array}{l}\text { Toronto \& } \\
\text { Vancouver }\end{array}$ \\
\hline $\begin{array}{l}\text { Malecki et al. } \\
2014\end{array}$ & $\begin{array}{l}50-64(\mathrm{n}=311) \\
\geq 65(\mathrm{n}=121)\end{array}$ & $(\mathrm{n}=939)$ & $\begin{array}{l}\text { Cross sectional } \\
\text { Mixed methods }\end{array}$ & High & $\begin{array}{l}\text { United } \\
\text { States }\end{array}$ & Wisconsin \\
\hline $\begin{array}{l}\text { Mathis et al. } \\
2015\end{array}$ & $\geq 65$ & $(n=217)$ & $\begin{array}{l}\text { Cross sectional } \\
\text { Mixed methods }\end{array}$ & High & $\begin{array}{l}\text { United } \\
\text { States }\end{array}$ & Flint, Michigan \\
\hline $\begin{array}{l}\text { Ory et al. } \\
2016\end{array}$ & $\geq 60$ & $(n=272)$ & $\begin{array}{l}\text { Cross sectional } \\
\text { Quantitative }\end{array}$ & Medium & $\begin{array}{l}\text { United } \\
\text { States }\end{array}$ & Texas \\
\hline $\begin{array}{l}\text { Ottoni et al. } \\
2016\end{array}$ & $\geq 60$ & $\begin{array}{l}2012(\mathrm{n}=28) \\
2014(\mathrm{n}=22)\end{array}$ & $\begin{array}{l}\text { Longitudinal } \\
\text { Mixed methods }\end{array}$ & Medium & Canada & Vancouver \\
\hline $\begin{array}{l}\text { Rantakokko et } \\
\text { al. } 2012\end{array}$ & $75-81$ & $(\mathrm{n}=214)$ & $\begin{array}{l}\text { Longitudinal } \\
\text { Quantitative }\end{array}$ & Medium & Finland & Jyväskylä \\
\hline $\begin{array}{l}\text { Rioux \& } \\
\text { Werner } 2011\end{array}$ & 72 to 86 & $(n=103)$ & $\begin{array}{l}\text { Cross sectional } \\
\text { Mixed methods }\end{array}$ & Medium & France & Central \\
\hline $\begin{array}{l}\text { Roe et al. } \\
2017\end{array}$ & $\begin{array}{l}16 \text { to } \geq 64 \\
47 \% 64-87\end{array}$ & $(\mathrm{n}=406)$ & $\begin{array}{l}\text { Cross sectional } \\
\text { Mixed methods }\end{array}$ & Medium & Scotland & Central \\
\hline $\begin{array}{l}\text { Scott et al. } \\
2011\end{array}$ & $54-91$ & $(n=282)$ & $\begin{array}{l}\text { Cross sectional } \\
\text { Mixed methods }\end{array}$ & Medium & $\begin{array}{l}\text { United } \\
\text { States } \\
\end{array}$ & $\begin{array}{l}\text { Northern } \\
\text { Indiana } \\
\end{array}$ \\
\hline $\begin{array}{l}\text { Strobl et al. } \\
2016\end{array}$ & 65 to 92 & $(n=78)$ & $\begin{array}{l}\text { Cross sectional } \\
\text { Qualitative }\end{array}$ & Medium & Germany & $\begin{array}{l}\text { Augsburg \& } \\
\text { Gersthofen }\end{array}$ \\
\hline $\begin{array}{l}\text { Tiernan et al. } \\
2013\end{array}$ & 55 to 90 & $(\mathrm{n}=501)$ & $\begin{array}{l}\text { Cross sectional } \\
\text { Quantitative } \\
\end{array}$ & Medium & $\begin{array}{l}\text { United } \\
\text { States } \\
\end{array}$ & Detroit \\
\hline $\begin{array}{l}\text { Tilley et al. } \\
2017\end{array}$ & $\geq 65$ & $(n=43)$ & $\begin{array}{l}\text { Cross sectional } \\
\text { Mixed methods }\end{array}$ & Medium & Scotland & Edinburgh \\
\hline $\begin{array}{l}\text { Tiraphat et al. } \\
2017\end{array}$ & $\geq 60$ & $(n=4183)$ & $\begin{array}{l}\text { Cross sectional } \\
\text { Mixed methods }\end{array}$ & Medium & Thailand & Four regions \\
\hline $\begin{array}{l}\text { Toma et al. } \\
2015\end{array}$ & $\begin{array}{l}\text { Mean age } \\
64.1 \pm 9.3 \\
\end{array}$ & $(n=6134)$ & $\begin{array}{l}\text { Longitudinal } \\
\text { Mixed methods }\end{array}$ & Medium & England & \\
\hline $\begin{array}{l}\text { Van Cauwen- } \\
\text { berg et al. } 2016\end{array}$ & $\begin{array}{l}\text { Mean age } \\
71.9 \pm 6.2 \\
\end{array}$ & $(n=1131)$ & $\begin{array}{l}\text { Cross sectional } \\
\text { Mixed methods }\end{array}$ & Medium & Belgium & Flanders \\
\hline $\begin{array}{l}\text { Vine et al. } \\
2012\end{array}$ & $57-87$ & $(\mathrm{n}=12)$ & $\begin{array}{l}\text { Cross-sectional } \\
\text { Qualitative }\end{array}$ & High & Australia & Brisbane \\
\hline $\begin{array}{l}\text { Völker et al. } \\
2013\end{array}$ & 16 to 80 & $(n=42)$ & $\begin{array}{l}\text { Cross sectional } \\
\text { Mixed methods }\end{array}$ & Medium & Germany & $\begin{array}{l}\text { Dusseldorf \& } \\
\text { Cologne }\end{array}$ \\
\hline $\begin{array}{l}\text { Ward Thomp- } \\
\text { son et al. } 2014\end{array}$ & $\geq 65$ & $(n=61)$ & $\begin{array}{l}\text { Longitudinal } \\
\text { Mixed methods }\end{array}$ & Medium & $\begin{array}{l}\text { United } \\
\text { Kingdom }\end{array}$ & $\begin{array}{l}\text { England, Wales } \\
\& \text { Scotland }\end{array}$ \\
\hline $\begin{array}{l}\text { Wong et al. } \\
2017\end{array}$ & $\geq 60$ & $(\mathrm{n}=719)$ & $\begin{array}{l}\text { Cross sectional } \\
\text { Mixed methods }\end{array}$ & Medium & China & Hong Kong \\
\hline $\begin{array}{l}\text { Yahaya et al. } \\
2012\end{array}$ & $\geq 60$ & $(n=2980)$ & $\begin{array}{l}\text { Cross sectional } \\
\text { Quantitative }\end{array}$ & Medium & Malaysia & \\
\hline $\begin{array}{l}\text { Yu et al. } \\
2017\end{array}$ & $\geq 60$ & $(\mathrm{n}=181)$ & $\begin{array}{l}\text { Cross sectional } \\
\text { Quantitative }\end{array}$ & High & $\begin{array}{l}\text { Hong } \\
\text { Kong }\end{array}$ & $\begin{array}{l}\text { Sha Tin \&Tai } \\
\text { Po }\end{array}$ \\
\hline $\begin{array}{l}\text { Zandieh et al. } \\
2017\end{array}$ & $\geq 65$ & $(\mathrm{n}=173)$ & $\begin{array}{l}\text { Cross sectional } \\
\text { Mixed methods }\end{array}$ & High & England & Birmingham \\
\hline $\begin{array}{l}\text { Zuniga-Teran } \\
\text { et al. } 2017\end{array}$ & $46.4 \% \geq 60$ & $(\mathrm{n}=486)$ & $\begin{array}{l}\text { Cross sectional } \\
\text { Quantitative }\end{array}$ & Medium & $\begin{array}{l}\text { United } \\
\text { States }\end{array}$ & Tucson, Arizona \\
\hline
\end{tabular}




\section{Topic Areas}

Topic areas within neighbourhood domains developed iteratively as analyses of the articles evolved. The final five domains include Neighbourhood Features, Transport Environment, Destinations and Land Use, Social Environment and Connectivity. Of the five domains that incorporate specific features in the urban environment, Neighbourhood Features (40/49) and Social Environment references (38/49) are present in most of the articles, followed by Transport Environment (19/49), Connectivity (18/49), and Destinations and Land Use (18/49). References in Table 2 show that considerable overlap occurred across the domains, within and between the studies. Following on from Table 2, major findings are summarised within neighbourhood domains. 
Table 2. Assessment of Urban Environment Domains and Health and Well-being Outcomes

\begin{tabular}{|c|c|c|c|}
\hline Domain & Features & $\begin{array}{l}\text { Health and } \\
\text { well-being }\end{array}$ & Reference \\
\hline $\begin{array}{l}\text { Neighbour- } \\
\text { hood } \\
\text { Features }\end{array}$ & $\begin{array}{l}\text { Presence of services } \\
\& \text { recreation } \\
\text { facilities, aesthetic } \\
\text { quality, street lights, } \\
\text { air quality, quietness, } \\
\text { natural features }\end{array}$ & $\begin{array}{l}\text { Physical } \\
\text { activity, health } \\
\text { and well-being }\end{array}$ & $\begin{array}{l}\text { Adams et al., 2012; Blay et al., 2015; Bjornsdottir et al., 2012; Brookfield et al., 2017;Chaudhury et al., 2016; } \\
\text { Chudyk et al., 2015; Day, 2010: De Donder et al., 2013; Dong \& Bergren., 2017; Douma et al., 2017; Eibich et al., } \\
\text { 2016; Gale et al., 2011; Gao et al., 2017; Gardner, 2011; Gauvin et al., 2012; Giehl et al., 2012; Giraldez-Garcia et } \\
\text { al., 2013; Hayward et al., 2015; Huong et al., 2012; Jones et al., 2014; Kearns et al., 2015; Kent et al., 2017; Kolbe- } \\
\text { Alexander et al., 2015; Lo et al., 2017; Mahmood et al., 2012; Ory et al., 2016; Ottoni et al., 2016; Rantakokko et } \\
\text { al., 2012; Rioux \& Werner., 2011; Scott et al., 2011; Strobl et al., 2016; Tilley et al., 2017; Toma et al., 2015; Ward } \\
\text { Thompson et al., 2014; Tiraphat et al., 2017; Van Cauwenberg et al., 2016; Völker et al., 2013; Wong et al., 2017; } \\
\text { Yahaya et al., 2012; Zandieh et al., 2017. }\end{array}$ \\
\hline $\begin{array}{l}\text { Destinations } \\
\& \text { Land Use }\end{array}$ & $\begin{array}{l}\text { Residential density, } \\
\text { land use diversity, } \\
\text { natural space access }\end{array}$ & $\begin{array}{l}\text { Physical } \\
\text { activity, health } \\
\text { and well-being }\end{array}$ & $\begin{array}{l}\text { Adams et al., 2012; Browne-Yung., 2016; Chudyk et al., 2015; Day, 2010; De Donder et al., 2013; Douma et al., } \\
\text { 2017; Gardner, 2011; Giehl et al., 2012; Kolbe-Alexander et al., 2015; Lo et al., 2017; Malecki et al., 2014; Ory et } \\
\text { al., 2016; Roe et al., 2017; Tilley et al., 2017; Vine et al., 2012; Völker et al., 2013; Yu et al., 2017; Zandieh et al., } \\
\text { 2017. }\end{array}$ \\
\hline Connectivity & $\begin{array}{l}\text { Ease of access, } \\
\text { continuity of } \\
\text { connectivity to } \\
\text { services, crossing }\end{array}$ & $\begin{array}{l}\text { Physical } \\
\text { activity, health } \\
\text { and well-being }\end{array}$ & $\begin{array}{l}\text { Adams et al., 2012; Bjornsdottir et al., 2012; Brookfield et al., 2017; Chaudhury et al., 2016; Day, 2010; De } \\
\text { Donder et al., 2013; Ferreira et al., 2010; Gauvin et al., 2012; Giehl et al., 2012; Mahmood et al., 2012; Malecki et } \\
\text { al., 2014; Rantakokko et al., 2012; Strobl et al., 2016; Tilley et al., 2017; Van Cauwenberg et al., 2016; Vine et al., } \\
\text { 2012; Ward Thompson et al., 2014; Zuniga-Teran et al., 2017. }\end{array}$ \\
\hline
\end{tabular}
density, sidewalks quality 


\section{Neighbourhood Features}

Characteristics of the city neighbourhood domain included one or more of the following features: presence of services and recreation facilities, aesthetic quality, street lights, air quality and noise level, quietness, natural features which in turn were associated with physical activity and health and wellbeing outcomes assessed. Neighbourhood Features are cited in 40/49 of the articles.

\section{Services \& Recreation Facilities}

Respondents living within proximity to a well-serviced area walked more often over time (Gauvin et al., 2012); similarly, in Chudyk et al. (2015), participants made three trips a day, mostly to grocery stores, malls and cafés. Complaints raised by $43.1 \%$ of participants in the Belgian Ageing Studies project (De Donder et al., 2013) included a shortage of benches; in addition, nearly one in four indicated their neighbourhood lacked practical services and recreation facilities and reported feeling unsafe when distances were too far.

Satisfaction with community services related significantly to self-rated health and functional independence (Giraldez-Garcia et al., 2013). Features regarded as important for well-being included access to activities and amenities, more so than aspects of health and place (Douma et al., 2017). Public places access, such as cafés, post offices, and parks were key informal public life opportunities identified by Gardner (2011). Access to local services and community centres with varied exercise programmes were perceived as physical activity facilitators (Mahmood et al., 2012). Recreation centres in low inequality areas encouraged walking, conversely lack of recreation centres in high inequality areas did not encourage walking (Zandieh et al., 2017). Leisure time physical activity was lower with more limited access and proximity to services and facilities (Kolbe-Alexander et al., 2015).

Availability of benches was identified as an important neighbourhood physical activity facilitator (Bjornsdottir, Arnadottier and Halldorsdottier, 2012; Ottoni et al., 2016; van Cauwenberg et al., 2016); a welcoming resting point (Brookfield, Thompson and Scott, 2017); and as an important physical and social aspect of the neighbourhood (Mahmood et al., 2012).

Significant age-friendly predictors of quality of life included attractive aesthetics and access to services (Tiraphat et al., 2017) and residential satisfaction depended on location with accessibility to local services in $70 \%$ of people (Rioux and Werner, 2011).

\section{Aesthetic Quality}

People who rated their neighbourhood as being of lower quality were more likely than other respondents to report feelings of loneliness (Kearns et al., 2015) and negative environment features were perceived as functional limitations (Rantakokko et al., 2012). Lack of neighbourhood cleanliness contributed to stress (Scott, Jackson and Bergeman, 2011) and Hayward et al. (2015) identified it as a barrier to health. People reporting the presence of neighbourhood disorder were more likely to have a fair or poor quality of life (Dong and Bergren, 2017) and less enjoyment, lower levels of autonomy and self-realisation 
measured over two waves of the national English Longitudinal Study of Ageing (Toma, Hamer and Shankar, 2015). By comparison, people who reported fewer problems with their neighbourhood had higher levels for mental well-being (Gale et al., 2011) that was also associated with higher rated perceived aesthetic quality (Gao et al., 2017; Kent, Ma and Mulley, 2017). High satisfaction with outdoor spaces and buildings was significantly associated with increased odds of reporting good selfrated health by $>20 \%$ of people (Wong, Yu and Woo, 2017). Adverse environment conditions, established in an internal and external built environment index drawn up by Blay et al. (2015), were significantly associated with poorer health in 12 of 19 health conditions. In addition, the index was significantly associated with lifestyle health-related behaviours such as decreased physical activity, increased tobacco and alcohol use (ibid).

\section{Street Lights}

Barriers to activity included specific contexts and inadequate night time lighting (Bjornsdottir, Arnadottier and Halldorsdottier, 2012; Giehl et al., 2012; Mahmood et al., 2012; Strobl et al., 2016). For example, roads with poor lighting and waiting for public transport at a bus or train station at night (Strobl et al., 2016); sidewalk obstructions and lighting (Mahmood et al., 2012); poor lighting and fear of the dark (Bjornsdottir, Arnadottier and Halldorsdottier, 2012).

\section{Air Quality and Noise Level}

Air pollution was perceived to affect breathing and health in Scotland (Day, 2010) and the elderly living in a rural area were aware that their environment had better air quality and relative quietness in comparison to the city in Vietnam (Huong et al., 2012). Although a peaceful restorative view of the Rhine was appreciated, a high degree of noise was also noted (Völker and Kistemann, 2013). Public seating away from heavy traffic in pleasant surroundings and near local services encouraged people to be outside (Day, 2010) while loud noise reported from traffic and other sources and seeing vandalism was correlated in Chicago (Dong and Bergren, 2017). Air pollution affected mental health more in the older group and higher noise levels were associated with worse mental health in both older ( $\mathrm{n}=993)$ and younger ( $\mathrm{n}=312$ ) residents in Berlin (Eibich et al., 2016). Pollution was perceived to impact on safety by $82.6 \%$ of participants in Malaysia (Yahaya et al., 2012). Likewise, safety concerns were raised due to neighbourhood noise and pollution (Huong et al., 2012).

\section{Quietness \& Natural Features}

Walking in a quiet natural urban space with flowers in Edinburgh appeared to bring pleasure and was calming according to objectively measured electroencephalography output (Tilley et al., 2017). Poor physical activity levels were associated with low recreation, park and poor aesthetics profiles (Adams et al., 2012). Similarly, Ward Thompson et al, (2014) found that outdoor physical activity depended on the presence of a local park, while physical activity was frequently undertaken at home or within one to three blocks of home in Chaudhury et al. (2016). Facilitators for outdoor activities included access 
to trails, hiking and fishing in Montana (Lo et al., 2017). Conversely, less attractive scenery and fewer open spaces discouraged walking (Zandieh et al., 2017). Ory et al. (2016) found that $75 \%$ of participants preferred to walk in neighbourhood streets, followed by green areas $34 \%$, malls $25 \%$.

\section{Transport Environment}

The transport environment domain includes aspects such as the walking and cycling infrastructure, pedestrian and traffic safety and public transport. These were associated with well-being and perceptions of neighbourhood walkability and safety and cited in 19/49 articles.

\section{Walking \& Cycling Infrastructure}

Significant age-friendly predictors of quality of life included provision of places for walking (Tiraphat et al., 2017). However, hilly topography and pedestrian and cycling conflict on shared pathways undermined walkability (Vine, Buys and Aird, 2012). Likewise, barriers to physical activity included hills near to the residential building (Bjornsdottir, Arnadottier and Halldorsdottier, 2012). Walking was the preferred activity by $42 \%$ of the sample in Flanders, followed by cycling $34 \%$ and motorised transport 23\% (van Cauwenberg et al., 2016). Perception of whether a built environment supported walkability had stronger effects on life satisfaction than objective measures of walkability (Kent, Ma and Mulley, 2017). Ory et al. (2016) found that preferred places to walk were neighbourhood streets and participants reporting poor mental health $\geq 2$ days per month were $65 \%$ less likely to report frequent walking behaviours than those reporting fewer poor mental health days.

Every 10-point increase in the Street-Smart Walk Score measuring walkability in Vancouver was associated with a $20 \%$ increase in the number of average walking trips per day (Chudyk et al., 2015). Participants in a Brazilian study reported that suitable infrastructure for bike lanes, pedestrian paths or neighbourhood trails were important for activity choices such as walking along streets, sidewalks and public spaces (Giehl et al., 2012). Between one third and over $40 \%$ of $67-84$-year-olds living in a wellserviced urban area reported walking often (5-7 days per week) across three measured periods, yet between one fifth and one fourth of the participants reported never walking outside the home over a three-year period (Gauvin et al., 2012).

Leisure time physical activity was a main contributor for participants in a higher rated socioeconomic area whereas transport-related activity was the main contributor in a lower socio-economic area (Kolbe-Alexander et al., 2015). Urban environment improvements influenced positively on perceptions of walkability and safety at night but not on overall activity, self-rated health or quality of life (Ward Thompson et al., 2014). 


\section{Pedestrian \& Traffic Safety}

In Zuniga-Teran et al. (2017) walking and traffic safety related significantly. Similarly, walkability rating and walking time were positively associated with traffic safety and significantly higher scores for well-being (Yu et al., 2017). Traffic volume and speed determined predominant walking choices (Van Cauwenberg et al., 2016). Four out of ten adults complained about heavy street traffic and road safety problems in De Donder et al. (2013), which correlated highly with feelings of unsafety. Perceived unsafe traffic conditions correlated with sidewalks and curbs that were in disrepair (Dong and Bergren, 2017), and Malecki et al. (2014) identified that the presence of pedestrian islands aided safety for crossing streets.

\section{Public Transport}

Poor physical activity was associated with, but not limited to, low transport access (Adams et al., 2012). Important features identified in Toronto and Vancouver were the availability of bus shelters, bus frequency and bus routes (Mahmood et al., 2012) while accessibility to public transport was associated with increased well-being (Eibich et al., 2016). Poor public transport quality meant people preferred to use their cars (Vine, Buys and Aird, 2012).

\section{Destinations and land use}

This domain is comprised of one or more local aspects such as residential density, land-use mix diversity and natural open space access. These aspects were associated with physical activity, active transport, self-rated health and well-being and cited in 18/49 articles.

\section{Residential density}

Adams et al. (2012) found that poor activity was associated with low residential density and land-use mix plus low access to walking/cycling infrastructures, parks and recreation facilities, whereas best activity outcomes took place in high walkable and recreationally dense neighbourhoods. Moderate to poor physical activity was often associated with single vs. multi-family units in Malecki et al. (2014). In addition, prevalence of non-residential destinations was higher in neighbourhoods with individuals meeting recommended guidelines for physical activity (Malecki et al., 2014). Contrariwise, residential density was not related to outdoor physical activity (Zandieh et al., 2017).

\section{Land-use mix}

The land-use mix access score was significantly higher and related to active transport for the lower socio-economic group (Kolbe-Alexander et al., 2015); whereas significantly more leisure time physical activity was reported by residents living in a higher socio-economic area with a lower land-use mix score. In Gardner (2011) key sites for informal public life activity and participation included accessing 
diverse land-use facilities such as parks, cafés, post offices and main streets. Similarly, multiple destination access and interesting things to look at contributed to active community engagement (Malecki et al., 2014). Land-use mix access and perceived walkability were associated with significantly higher scores for life satisfaction, happiness and less loneliness (Yu et al., 2017). Chosen places to walk included access to a high land-use mix such as streets, green areas, malls, gyms and schools (Ory et al., 2016) while local shops within walking distance highlighted the importance of mixed land-use patterns for walkability (Vine, Buys and Aird, 2012).

\section{Natural open space access}

Pleasant appealing surroundings away from traffic facilitated and supported walking (Day, 2010) as did access to trails, hiking and fishing (Lo et al., 2017). Safety, nature access and being outside were important aspects of subjective well-being in females compared to males (Douma et al., 2017). Probability of low-stress seniors living in deprived neighbourhoods having a garden was $61 \%$ and living near to green space $75 \%$; they also rated they were very satisfied/satisfied with the area (Roe, Aspinall and Thompson, 2017). The most common exercise destinations in Chudyk et al. (2015) were neighbourhoods, natural environments and recreation centres. Low spatial inequalities and attractive destinations encouraged walking whereas lack of green and attractive destinations discouraged walking (Zandieh et al., 2017). Access to green areas for physical activity rated as an important factor by $67 \%$ of participants in Giehl et al. (2012). A study comparing contrasting income areas in Australia found that Burnside participants who had positive perceptions of green spaces and lack of crime encouraged their physical activity, whereas Playford residents reported a lack of green spaces and discouraging presence of incivilities (Browne-Yung, Ziersch and Baum, 2016). Approximately 25\% of participants in the Belgian Ageing Studies project indicated there were insufficient green spaces and parks (de Donder et al., 2013). Access to promenades for activities or peaceful viewing of the Rhine were favourite places to spend restorative time (Völker and Kistemann, 2013). Green urban space access was perceived to be calming and quieter in subjective interviews and objectively confirmed on electroencephalography (Tilley et al., 2017).

\section{Social Environment}

This domain includes social capital aspects such as perception of safety from crime, neatness, reputation, neighbourhood cohesion (neighbourliness) and accessibility to neighbourhood and recreational amenities, which were associated with physical activity and health and well-being. Social Environment references are cited in 37/49 articles. 


\section{Perception of safety from crime}

Neighbourhood safety, engagement perceptions and health and well-being were correlated (Tiernan $e t$ al., 2013). Participants with poor self-rated health were $21 \%$ more likely to report fear of crime and twice as likely to have chronic conditions, compared to those with excellent self-rated health (Mathis, Rooks and Kruger, 2015). Significant age-friendly predictors of quality of life were places free of crime, with social trust, cohesion and support (Tiraphat et al., 2017). Neighbourhood safety was a significant predictor for perceived quality of life (Yahaya et al., 2012); conversely, older participants' $\geq 85$ years highlighted the importance of home and did not mention the outdoor environment, garden or safety (Douma et al., 2017). Higher scores for perceived safety from crime were associated with higher levels of moderate to vigorous physical activity (Kolbe-Alexander et al., 2015) and daytime safety was an activity facilitator (Giehl et al., 2012). In a comparison of neighbourhoods perceived lack of crime encouraged activity which impacted positively on health and well-being in Burnside, whereas Playford incivilities and perceived poor reputation and disorder impacted negatively on health and well-being (Browne-Yung, Ziersch and Baum, 2016). People with poor self-rated health were $21 \%$ more likely to report fear of crime compared to those with excellent self-rated health, and 6\% more likely to participate less in social activities and 3\% more likely to experience racism (Mathis, Rooks and Kruger, 2015). Concerns about crime, poor lighting and fear of the dark moderated choices to go out (Bjornsdottir, Arnadottier and Halldorsdottier, 2012), while facilitators for activity included going for walks together. Neighbourhood concerns included fear of being robbed (Ferreira et al., 2010), and although perception of drug threat was common, $81.5 \%$ of residents felt safe in their neighbourhood (Yahaya et al., 2012).

\section{Neatness \& reputation}

Negative perceptions of environment features and times of day led to avoidance behaviour (Brookfield, Thompson and Scott, 2017) and outdoor activity prevalence depended upon a nuisance-free local park (Ward Thompson et al., 2014). Likewise, perceived social disorder discouraged walking (Zandieh et al., 2017). Feeling of belonging and social cohesion had the strongest relationship with mental wellbeing but as perceptions of social environment incivilities increased well-being decreased (Jones et al., 2014). Perceptions of antisocial behaviours were associated with three or more reported neighbourhood problems and frequent loneliness (Kearns et al., 2015). Greater perceived neighbourhood incivility and crime were significantly associated with less enjoyment in life, lower sense of autonomy and poorer overall well-being at baseline and follow up assessment (Toma, Hamer and Shankar, 2015). The more that disorder, degeneration and physical incivilities were experienced the more feelings of unsafety were reported (de Donder et al., 2013). Loud noise was reported emanating from neighbours, traffic or other sources by $43.9 \%$ of a study of Chinese elderly in Chicago (Dong and Bergren, 2017); loud noise related to aggression, particularly at night, was disliked (Day, 2010). 


\section{Neighbourhood cohesion}

Social participation, perceived social inclusion and age-friendliness of built environments was associated with the likelihood of reporting good health (Wong, Yu and Woo, 2017). Seniors with poorer health and well-being were less likely to be active (49\%) but likely to have good social well-being (Roe, Aspinall and Thompson, 2017). The most important domains selected for well-being were social life, activities, health, space and place (Douma et al., 2017). Higher levels of perceived social support were associated with significantly greater mental well-being while people less emotionally stable had a lower sense of cohesion and were more likely to score higher for perceived neighbourhood problems (Gale $e t$ al., 2011). Perceived well-connected community and an aesthetically pleasing environment were associated with life satisfaction (Kent, Ma and Mulley, 2017). Promenade users reported strong place attachment (Völker and Kistemann, 2013) and perceived social unity and interaction was positively associated with well-being that influenced collective place attachment (Gao et al., 2017). People reporting low social cohesion were 66\% less likely to report frequent walking (Ory et al., 2016) whereas invitations to be active from friends or neighbours were positively associated with physical activity (Giehl et al., 2012). Likewise, neighbourhood social environment and sense of community had a positive influence on physical activity (Chaudhury et al., 2016; Yu et al., 2017) and was significantly associated with walking (Zuniga-Teran et al., 2017).

Friendship and neighbourhood cohesion identified as important facilitators for community participation (Strobl et al., 2016). Likewise, social interactions were significant for both the older, >65 years, and younger group, <65 years, but more so for the older group (Jones et al., 2014). Residential satisfaction corresponded with location and satisfaction with neighbour relations rather than behavioural aspects (Rioux and Werner, 2011). The presence of benches in the neighbourhood contributed to cohesion and social capital (Mahmood et al., 2012; Ottoni et al., 2016).

Physical health linked to a sense of purposeful community engagement (Huong et al., 2012; Tiernan et al., 2013). Positive mood states, measured on electroencephalography, were elicited when people were greeted on their walk, whereas lack of acknowledgement led them to feel more negative about the environment (Tilley et al., 2017). Huong et al. (2012) found that participants rated the environment, physical health, social interaction, financial status and religion as important dimensions of quality of life. The highest risk group for perceived stress in later life was social isolation with loneliness being especially detrimental to health and well-being (Scott, Jackson and Bergeman, 2011).

\section{Accessibility to neighbourhood and recreational amenities}

Access to local amenities for social contact in Mahmood et al. (2012) was rated important. In Chudyk et al. (2015) the most common destinations for socialisation and eating out were restaurants, cafés and private residences. Social support associations rated significant for life and health satisfaction in older, $\geq 60$ years, residents, whereas there was no discernible impact on health and well-being of the younger residents (Eibich et al., 2016). Satisfaction with physical and social environments was associated with 
better self-rated health; contrary satisfaction with community services was associated with depression and chronic medical conditions (Giraldez-Garcia et al., 2013). Occasional or frequent loneliness was reported by people who did not feel part of their community, compared to those who did, while those (44\%) who used the fewest local amenities compared to those who used the most (34\%) also reported more loneliness (Kearns et al., 2015). Significant predictors for health and well-being were the length of time lived in the neighbourhood and access to social club membership (Jones et al., 2014).

\section{Connectivity}

This domain includes one or more of the following aspects: ease of access, continuity of street connectivity to services, intersection density, sidewalks quality that are associated with health and wellbeing, active commuting, physical activity and are cited in 18/49 articles.

\section{Ease of access}

Women who had a car, who perceived user-friendliness of walking environments to be poor and whose depression scale scores were higher, had a lower likelihood of walking more often (Gauvin et al., 2012). Outdoor barriers increased walking difficulty almost threefold (Rantakokko et al., 2012) while obstacles to community participation included poor health, poorly designed access and municipal infrastructure (Strobl et al., 2016).

\section{Continuity of street connectivity to services}

Highest values of connectivity, land use and traffic safety meant walking for recreation and transport was significant (Zuniga-Teran et al., 2017). Conversely, low perceived walkable transit connectivity was associated with poor physical activity levels (Adams et al., 2012; Lo et al., 2017).

\section{Intersection density, sidewalks quality}

Pedestrians felt insecure on narrow pathways (Strobl et al., 2016), while narrow sidewalks with obstructions (Mahmood et al., 2012) were perceived activity barriers. Approximately $70 \%$ of participants considered sidewalk quality as regular or poor (Giehl et al., 2012) while the presence of bad quality sidewalks led to a perception of danger (de Donder et al., 2013). Barriers to physical activity included steps, uneven sidewalks and curbs that led to falls (Brookfield, Thompson and Scott, 2017). Similarly, high kerbs, large bins, heavy traffic and slopes (Day, 2010); converging vehicular and nonmotorised routes; and insufficient time allocated to cross the road at intersections (Vine, Buys and Aird, 2012) were barriers to walkability.

Outdoor activity facilitators included the presence of non-slippery sidewalks (Bjornsdottir, Arnadottier and Halldorsdottier, 2012), and even sidewalks for transportation walking (van 
Cauwenberg et al., 2016). The most frequent rate of physical activity was undertaken at home or close to home in a study across eight neighbourhoods in Vancouver and Portland (Chaudhury et al., 2016).

The residential street improvements programme 'Sustrans 'DIY' Streets' outcomes showed that paths to open spaces were easily walkable when attractive features existed in the local open space, however, there was no change in overall physical activity, quality of life and health and well-being (Ward Thompson et al., 2014). Having to look out for uneven paving and street obstacles elicited more events recorded on electroencephalography (Tilley et al., 2017).

Independence in activities of daily living was associated with working men $\leq 80$ years who were not concerned about leaving home because of fear of falling due to sidewalk defects (Ferreira et al., 2010). Adverse sidewalk conditions were associated with moderate to poor physical activity (Malecki et al., 2014; Lo et al., 2017).

\section{Discussion}

This literature review has been undertaken systematically using a rapid review method to gain a better understanding of ageing residents' perceptions of whether and, if so, how urban environment characteristics and features are perceived to influence their health and well-being. Some overarching topic areas emerged as health and well-being barriers or facilitators that were summarised in five domains. Within each domain that arose, specific features of the neighbourhood that influenced health and well-being were noted. These are summarised in this discussion bearing in mind WHO established Global Network of Age-friendly Cities and Communities domains (WHO, 2007) core indicators of equity, accessibility and inclusiveness (WHO, 2015).

Despite the increased focus of contemporary literature evaluating the links between cities and health, there is a distinct lack of prospective studies identifying direct causal relationships. Given that only three studies (3/49) asked the direct question of participants to identify the perceived neighbourhood features that contribute or detract from their health and well-being demonstrates a distinct paucity in the literature on this topic. Although neighbourhood features were seldom directly identified by participants as having an impact on their health and well-being, urban characteristics that mitigated or encouraged the choice to be active were identified as health and well-being determinants and interpreted as a proxy instead. Therefore, because walkability assessments and neighbourhood perceptions defined barriers and facilitators for activity these are regarded as proxy health and well-being determinants in this paper.

Perceived neighbourhood barriers and facilitators to health and well-being are place/context dependent. For example, leisure time physical activity was a main contributor for participants in a higher rated socio-economic area whereas transport-related activity was the main contributor in a lower socioeconomic area (Kolbe-Alexander et al., 2015). Then again, access to open spaces, walking and biking 
trails was higher in a neighbourhood with younger low-income participants (Malecki et al., 2014). There were significant associations between poor self-reported health and well-being, reduced physical activity, hypertension and a negatively perceived environment (Blay et al., 2015). Unsurprisingly, a comparison of perceived neighbourhood disorder, security and reputation across contrasting income areas in Adelaide showed that in Playford, a combined perceived lack of suitable green outdoor access and presence of graffiti, discarded needles and broken glass was not conducive to a sense of well-being (Browne-Yung, Ziersch and Baum, 2016). Conversely, positive perceptions by residents in Burnside who reported abundance of green spaces and lack of crime encouraged physical activity. In addition, Burnside residents reported significantly greater cohesion, neighbourliness, and sense of community whereas Playford residents perceived their neighbourhood was unsafe, unfriendly with a poor reputation and participants reported worse mental and physical health (Browne-Yung, Ziersch and Baum, 2016). Similar implications are seen in the self-reported neighbourhood indicators, forming part of the Built Environment Index drawn up by Blay et al. (2015), which included the presence of garbage collection and proper public street illumination; participants who reported three or more adverse conditions were $33 \%$ less likely to report adequate physical activity, compared to no adverse conditions reported.

Social inclusion in a city neighbourhood may be regarded as a health and well-being determinant. For example, with significance level alpha set at $\mathrm{p}<0.05$ for all statistical analysis, there were significant Spearman's rank correlation coefficient associations $(\mathrm{p}<.001)$ between community engagement, neighbourhood perceptions, and health and well-being (Tiernan et al., 2013). Perceived social inclusion in the neighbourhood was likely to be associated with good health (Eibich et al., 2016; Douma et al., 2017; Wong, Yu and Woo, 2017) whereas the converse, social isolation and loneliness, were detrimental (Scott, Jackson and Bergeman, 2011). Important social networks for ageing in place included sidewalks, parks, cafés, post offices while semi-public spaces such as porches, patios, backyards and balconies offered a convenient threshold for social interaction (Gardner, 2011). Social interactions with neighbours were also significantly associated with walking (Zuniga-Teran et al., 2017) and the neighbourhood social environment had a positive influence on physical activity (Chudyk et al., 2015; Chaudhury et al., 2016; Yu et al., 2017). Perceived social capital and the sense of belonging in a friendly neighbourhood encouraged and facilitated physical activity (Bjornsdottir, Arnadottier and Halldorsdottier, 2012); furthermore, invitations from friends or neighbours to engage in physical activities increased leisure time activity (Giehl et al., 2012). However, elderly who were less likely to be active were also likely to have good social well-being (Roe, Aspinall and Thompson, 2017), demonstrating that perceived social inclusion does not automatically mean an association with good health.

Perceived social support was associated with greater mental well-being (Gale et al., 2011; Jones et al., 2014; Gao et al., 2017) and people who used the fewest local amenities reported more loneliness (Kearns et al., 2015), which may suggest that they were either unhappy with the choice of activities on 
offer or were disinclined to participate for other reasons. Inclusion of measures of quality of local amenities and the transport routes to community centres are recommended in future studies. High satisfaction with community services significantly related to health and functional independence (Giraldez-Garcia et al., 2013), plus social support associations were rated significant for life and health satisfaction (Eibich et al., 2016). However, walkability and accessibility to amenities was not significantly related (Chaudhury et al., 2016). Neighbourhood social friendship and cohesion had a positive influence on physical activity, while voluntary social work activity was regarded as an important way to be socially active (Strobl et al., 2016). Volunteering is defined as a key subjective well-being determinant elsewhere (Brown, Abdallah and Townsley, 2017) and is linked with increased levels of well-being (Department of Health, 2014).

The availability of benches in the neighbourhood facilitated walking activity in the elderly as they provided an opportunity to rest (Bjornsdottir, Arnadottier and Halldorsdottier, 2012; Ottoni et al., 2016; Van Cauwenberg et al., 2016; Brookfield, Thompson and Scott, 2017), and doubled up as opportunities for socialising (Mahmood et al., 2012). Living in neighbourhoods with more accessible destinations resulted in more walking trips. For example, in Chudyk et al. (2015) the most common destinations for shopping or running errands included grocery stores, malls, health and personal care facilities and library and significant age-friendly predictors of quality of life included attractive aesthetics and access to services (Tiraphat et al., 2017). A high walkable recreationally dense environment profile was associated with best physical activity outcomes and lower body mass index levels in both Baltimore and Seattle-King County and Washington in Adams et al. (2012), suggesting that these environments are health and well-being facilitators and therefore salutogenic.

Barriers for moderate to poor physical activity were often associated with poor sidewalk conditions (Giehl et al., 2012; De Donder et al., 2013; Malecki et al., 2014); poorly maintained sidewalks or broken curbs (Dong and Bergren, 2017); lack of sidewalk continuity (Lo et al., 2017); narrow sidewalks, obstructions, inadequate lighting (Mahmood et al., 2012); and, defects that led to fear of falling (Ferreira et al., 2010; Bjornsdottir, Arnadottier and Halldorsdottier, 2012; Brookfield, Thompson and Scott, 2017). Furthermore, of interest and relevance for public health management providers such as local councils and clinical commissioning groups, is that reporting of outdoor barriers preceded the onset of mobility decline over time (Rantakokko et al., 2012).

Urban environment health and well-being facilitators for physical activity include diverse mixeduse land accessibility, increased urban density, street connectivity, accessibility to service and quality of the neighbourhood features (Adams et al., 2012; Malecki et al., 2014; Chudyk et al., 2015; KolbeAlexander et al., 2015), which is congruent with the literature (Renalds, Smith and Hale, 2010; Turrell et al., 2013; Sallis, Cerin, et al., 2016; Ward Thompson, Aspinall, et al., 2016). Greater activity is estimated to provide significant potential health benefits and reduce health-care costs (Zapata-Diomedi, Herrera and Veerman, 2016). 
Accessibility to green space and its effects on health and well-being were positively related, both with and without considering the amount of physical activity undertaken (Malecki et al., 2014). Seniors who rated they were very satisfied/satisfied with the local space were more likely to have access and live close to green space (Roe, Aspinall and Thompson, 2017). Less attractive scenery and lack of green spaces discouraged walking whereas the presence of green and attractive destinations encouraged walking (Lo et al., 2017; Zandieh et al., 2017) which is confirmed elsewhere (Giles-Corti et al., 2016; Chen et al., 2017). When participants were asked to reflect on neighbourhood design a significant proportion indicated there were insufficient green spaces and parks and that there was a lack of suitable green spaces to create a sense of well-being (De Donder et al., 2013). Furthermore, walking in a natural green space was preferred by participants and appeared to bring pleasure and was calming on electroencephalography output (Tilley et al., 2017).

Mental health is associated with walking. For example, in Ory et al. (2016) participants who reported poor mental health $\geq 2$ days per month were $65 \%$ less likely to report frequent walking behaviours than those reporting fewer poor mental health days. In addition, a significant association was reported between life satisfaction and mixed land-use access and perceived walkability (Yu et al., 2017) while mental well-being was higher in neighbourhoods where fewer problems were reported (Gale et al., 2011). Perception of whether a neighbourhood supports walkability and has a well-connected community also had strong effects on life satisfaction and happiness (Kent, Ma and Mulley, 2017).

Perceived neighbourhood safety or unsafety is associated with physical activity and health and wellbeing. Instinctively, it appears that crime, disorder and transport-related safety are particularly relevant considerations for the outdoor activity choices of the elderly. It stands to reason therefore that barriers to activity will have a direct consequence for health and well-being. For example, unsanitary environment conditions were identified to contribute to poor health (Hayward et al., 2015) and lack of cleanliness contributed to stress (Scott, Jackson and Bergeman, 2011). Fear of crime and poor self-rated health were also strongly associated (Mathis, Rooks and Kruger, 2015). Furthermore, a longitudinal study showed that greater perceived antisocial incivility and crime was significantly associated with less well-being at baseline and four years later (Toma, Hamer and Shankar, 2015). As perceptions of social incivilities increased well-being decreased (Jones et al., 2014); and, reported presence of neighbourhood disorder meant people were more likely to have a fair or poor quality of life (Dong and Bergren, 2017). Safety from crime was regarded as a predictor for quality of life (Tiraphat et al., 2017) and people with lower emotional stability who sensed less cohesion were likely to score higher for perceived neighbourhood problems (Gale et al., 2011). Barriers to active living included a fear of being robbed (Ferreira et al., 2010) while safety at night and concerns about enough lighting also impacted on choices to go out (Bjornsdottir, Arnadottier and Halldorsdottier, 2012). In addition, social disorder affected the walking rate (Ory et al., 2016). However, an anomaly in Yahaya et al. (2012) showed that despite the common perception of drug threat most residents felt safe (Yahaya et al., 2012). 
Satisfaction with the neighbourhood depended on accessibility to local services; however, although most elderly participants lived close to essential services they hesitated to go out because of safety concerns and transport quality (Rioux and Werner, 2011). People who were satisfied with life lived in a walkable neighbourhood with: contiguous streets, destination density and accessibility, and a cohesive community (Kent, Ma and Mulley, 2017). Perceived community safety was a key daytime physical activity facilitator (Adams et al., 2012; Giehl et al., 2012; Kolbe-Alexander et al., 2015; Browne-Yung; Chaudhury et al., 2016), which is supported by the literature (Stronegger, Titze and Oja, 2010; Bahrainy and Khosravi, 2013; Gao, Ahern and Koshland, 2016).

Air pollution was perceived to affect health (Day, 2010; Huong et al., 2012; Yahaya et al., 2012); perception of loud noise was associated negatively with mental health (Eibich et al., 2016) and reduced urban comfort level (Huong et al., 2012). Rural participants acknowledged that psychological health depended on feeling useful whereas both rural and urban groups agreed that the most important factor is a mind free from worry (Huong et al., 2012). Perceived social environment issues, environmental pollution, and noise were also a concern for urban elderly (Huong et al., 2012).

Renewed public health and well-being strategies are required to turn the tide on the inequities experienced within cities around the world. Updates by Public Health England (PHE) to the Wider Determinants of Health include density of food outlets, fine particulate matter levels in air pollution, economic inactivity and long-term unemployment levels (PHE, 2017), and evaluation of these criteria needs to be included in future research that examines neighbourhood characteristics associated with health and well-being. Direct associations between participant perceived urban environment characteristics and health and well-being outcomes are lacking in the literature, highlighting a need to examine their impact at individual and combined characteristic levels. This shortfall has been identified previously (Koohsari et al., 2015).

Limitations in this review are the exclusion of grey literature, and inclusion of only English published research. Multi-faceted methods used in the studies were not discussed, are worthy of indepth analysis and exploration in a separate paper. Although a recognised method of rapid review was undertaken systematically, there are areas within the review that warrant further in-depth analysis as a separate exercise such as the differences in results within studies that included more than one neighbourhood, plus outcomes across countries of origin.

Increasing participatory governance for health is becoming more commonplace with voluntary membership of public participation groups in the NHS (Public Participation Team, 2017) and Healthwatch England welcomed to strengthen patient and public participation to improve outcomes in health and social care delivery (Healthwatch England, 2018). It is recommended voluntary participation be extended to the elderly living in highly deprived areas in well-established older neighbourhoods to identify perceived neighbourhood health and well-being social and physical environment core indicator determinants at local level. Ongoing collaboration outcomes may then be incorporated in the monitoring 
and reporting mechanisms already in place, such as the English Indices of Deprivation and Joint Strategic Needs Assessment (Department for Communities and Local Government, 2015; NHS Portsmouth Clinical Commissioning Group, 2016).

Research outcomes in this review have far-reaching implications for age-friendly new build neighbourhood community design and regeneration projects policy solutions such as NHS Healthy New Towns (NHS, 2016), Age Friendly Transport (Bristol Ageing Better, 2018), and prioritising health in planning (Pineo, Chang and Pinto, 2015; Saunders and Transport for London, 2018). Health professionals, health governance stakeholders and city planners need to collaborate closely with communities to build and promote healthy cities by considering the eight WHO Age-friendly City Criteria to help cities aspire to become age-friendly (WHO, 2007). Further translation of findings may also inform the Building Research Establishment's International Healthy Cities Index (Pineo et al., 2018). In addition, although this review did not include dementia-related studies, it is timely to incorporate the design principles of dementia friendly neighbourhoods for life in planning principles (Mitchell \& Burton, 2010). The core indicators of equity, inclusivity and accessibility need to be translated to community design and outdoor space programs that consider physical, social and health service provision needs for the elderly (WHO Regional Office Europe, 2017).

This review found that perceptions of the neighbourhood play a pivotal role in the health and wellbeing of the elderly. These include fear of crime, the presence of social incivilities, sense of belonging and neighbourhood cohesion, presence of traffic and community safety, satisfaction with local services, social capital, access to facilities and open spaces, as well as seating areas. However, the development and validation of a theoretical framework that uses reliable valid measures of core indicators of equity, accessibility and inclusivity to rate both health and well-being and environmental characteristics consistently would add substantially to the evidence. In this way, real-world implications are generated to better inform and shape public health policies and planning practices for age-friendly environments in cities and communities.

\section{Conclusion}

This article and literature review contribute to the understanding of perceived environmental characteristics that facilitate or serve as barriers to the health and well-being of the elderly living in an urban environment.

Outcomes of this review show that perception of the environment plays a role in influencing physical health and mental well-being outcomes in the elderly. Examples of perceived predominant neighbourhood determinants facilitating health and well-being are those that encourage social interaction, invite participation in physical activity, promote active transport and present with greater variation in land use mix. These include perceived residential density, quality of the built environment, 
appearance, connectivity, transport accessibility, walkability, green access, safety and social cohesion. Examples of barriers to health and well-being include perceived neighbourhood disorder and incivility, lack of social capital, poor street and sidewalk quality, discontinuity and lack of safety. Of note particularly is that early identification of mobility barriers coincided with long-term impact on mobility choices.

However, what remains unclear is the role that perception of individual features or combination of features plays on health and well-being. Characteristics perceived to contribute to or detract from health and well-being in this review were indirectly represented in walkability assessment scoring tools; however, the question 'How do you think your environment contributes to your health and well-being?' was not asked in most of the studies and warrants further investigation, particularly amongst vulnerable elderly cohorts.

The contextual viewpoints of the elderly regarding environment features are an important consideration for future research involving environment assessment impact on the elderly. The effects of ageing on physiology means that movement becomes slower, therefore active transport infrastructures need to incorporate features such as the inclusion of traffic islands and resting places along a walking route. Establishing what works for and against health and well-being from the collective residents' perspective will help inform public health and neighbourhood community planning policy at localised level. Recommendations are made to encourage and engage public participation in research and particularly ask ageing residents, who are experts in the lived experience of their environment, to identify which neighbourhood characteristics they perceive have an impact on their health and wellbeing and how it does so.

This review contributes towards a more robust evidence base providing urban environment specific cues for health and well-being for architects and planners of new and regenerative community design projects. Delivery of public health provision that ensures safe equitable access to ageing-friendly active transport and community activities is a key priority. Including ageing residents in stakeholder discussions is pivotal to promote and sustain age-friendly city communities which will contribute to improved health and well-being for all in the long term.

\section{Disclosure statement}

No potential conflict of interest was reported by the authors.

\section{References}

Adams, M. A. et al. (2012) 'Neighborhood Environment Profiles for Physical Activity Among Older Adults', Journal Health Behaviour, 36(6), pp. 757-769. 
Ambrey, C. L. (2016) 'Urban greenspace, physical activity and wellbeing: The moderating role of perceptions of neighbourhood affability and incivility', Land Use Policy. Elsevier Ltd, 57, pp. 638644. doi: 10.1016/j.landusepol.2016.06.034.

Bahrainy, H. and Khosravi, H. (2013) 'The impact of urban design features and qualities on walkability and health in under-construction environments: The case of Hashtgerd New Town in Iran', Cities, 31, pp. 17-28. doi: 10.1016/j.cities.2013.01.001.

Beard, J. (2014) We were older then, we are younger now, WHO. World Health Organization. Available at: http://www.who.int/mediacentre/commentaries/ageing/en/ (Accessed: 26 November 2018).

Bell, P. A. et al. (2001) Environmental psychology. Fifth. Fort Worth: Harcourt College Publishers. Bjornsdottir, G., Arnadottier, S. A. and Halldorsdottier, S. (2012) 'Facilitators of and Barriers to Physical Activity in Retirement Communities: Experiences of Older Women in Urban Areas', Physical Therapy, 92(4), pp. 551-562.

Blair, S. N. (2009) '61 Physical inactivity: the biggest public health problem of the 21st Century', Journal of Science and Medicine in Sport, 10, p. 29. doi: 10.1016/s1440-2440(07)70066-x.

de Blasio, B. (2016) 'Healthier neighbourhoods through healthier parks', Comment 2850 www.thelancet.com, 388. doi: 10.1016/S0140-6736(16)30066-6.

Blay, S. L. et al. (2015) 'The relationship of the built environment to health-related behaviors and health outcomes in elderly community residents in a middle income country', Journal of Public Health Research, 4(548), pp. 135-141. doi: 10.4081/ija.2015.10.s1.708.

Booth, F. et al. (2017) 'Role of Inactivity in Chronic Diseases: Evolutionary Insight and Pathophysiological Mechanisms', Physiological Reviews, 97(4), pp. 1351-1402. doi: 10.1152/physrev.00019.2016.

Bristol Ageing Better (2018) News | Age Friendly Bristol, Age UK Bristol. Available at: http://agefriendlybristol.org.uk/news/ (Accessed: 28 September 2018).

Brookfield, K., Thompson, C. W. and Scott, I. (2017) 'The uncommon impact of common environmental details on walking in older adults', International Journal of Environmental Research and Public Health, 14(2). doi: 10.3390/ijerph14020190.

Brown, H., Abdallah, S. and Townsley, R. (2017) 'Understanding local needs for wellbeing data measures and indicators'. London: GOV.UK, pp. 1-62. Available at: https://www.whatworkswellbeing.org/product/understanding-local-needs-for-wellbeing-data/. 
Browne-Yung, K., Ziersch, A. and Baum, F. (2016) 'Neighbourhood, Disorder, Safety and Reputation and the Built Environment: Perceptions of Low Income Individuals and Relevance for Health', Urban Policy and Research. Routledge, 34(1), pp. 17-38. doi: 10.1080/08111146.2016.1138855.

van Cauwenberg, J. et al. (2016) 'Street characteristics preferred for transportation walking among older adults: A choice-based conjoint analysis with manipulated photographs', International Journal of Behavioral Nutrition and Physical Activity. BioMed Central, 13(1), pp. 1-17. doi: 10.1186/s12966016-0331-8.

Chang, M. (2016) Building the foundations - tackling obesity through planning and development, Town Country Planning Association. London. Available at: http://www.local.gov.uk/publications//journal_content/56/10180/7716564/PUBLICATION.

Chaudhury, H. et al. (2016) 'Neighbourhood environment and physical activity in older adults', Social Science \& Medicine, 149, pp. 104-113. doi: 10.1016/j.socscimed.2015.12.011.

Chen, H. et al. (2017) 'Does where you live matter to your health? Investigating factors that influence the self- rated health of urban and rural Chinese residents: evidence drawn from Chinese General Social Survey data', Health and Quality of Life Outcomes. BioMed Central, 15(78), pp. 1-11. doi: 10.1186/s12955-017-0658-0.

Chudyk, A. M. et al. (2015) 'Destinations matter: The association between where older adults live and their travel behavior', Journal of Transport \& Health. Elsevier, 2(1), pp. 50-57. doi: 10.1016/J.JTH.2014.09.008.

Critical Appraisal Skills Programme (2017) CASP Checklists. Available at: http://www.caspuk.net/casp-tools-checklists (Accessed: 4 May 2017).

Day, R. (2010) 'Environmental justice and older age: Consideration of a qualitative neighbourhoodbased study', Environment and Planning A, 42(11), pp. 2658-2673. doi: 10.1068/a43109.

Department for Communities and Local Government (2015) 'The English Indices of Deprivation 2015 Statistical Release'. London: GOV.UK, pp. 1-38. Available at: https://www.gov.uk/government/consultations/updating-the-english-indices-of-deprivation.

Department of Health (2014) 'What Works To Improve Wellbeing? A Compendium of Factsheets: Wellbeing Across the Lifecourse'. London: GOV.UK, pp. 1-8.

de Donder, L. et al. (2013) 'Perceptual quality of neighbourhood design and feelings of unsafety', Ageing and Society. Cambridge University Press, 33(06), pp. 917-937. doi:

10.1017/S0144686X12000207. 
de Vries, S. et al. (2013) 'Streetscape greenery and health: Stress, social cohesion and physical activity as mediators', Social Science \& Medicine, 94, pp. 26-33. doi:

10.1016/j.socscimed.2013.06.030.

Dong, X. Q. and Bergren, S. M. (2017) 'The Associations and Correlations between Self-reported Health and Neighborhood Cohesion and Disorder in a Community-dwelling U.S. Chinese Population', Gerontologist, 57(4), pp. 679-695. doi: 10.1093/geront/gnw050.

Douma, L. et al. (2017) 'Exploring subjective well-being in older age by using participant-generated word clouds', Gerontologist, 57(2), pp. 229-239. doi: 10.1093/geront/gnv119.

Eibich, P. et al. (2016) 'Associations between neighborhood characteristics, well-being and health vary over the life course', Gerontology, 62(3), pp. 362-370. doi: 10.1159/000438700.

Featherstone, R. M. et al. (2015) 'Advancing knowledge of rapid reviews: An analysis of results, conclusions and recommendations from published review articles examining rapid reviews', Systematic Reviews. BioMed Central, 4(1), pp. 1-8. doi: 10.1186/s13643-015-0040-4.

Ferreira, F. R. et al. (2010) 'Aging and urbanization: The neighborhood perception and functional performance of elderly persons in belo horizonte metropolitan area-Brazil', Journal of Urban Health, 87(1), pp. 54-66. doi: 10.1007/s11524-009-9406-z.

Fioramonti, L. (2017) Wellbeing Economy: Success in a World Without Growth. Johannesburg: Pan Macmillan South Africa. Available at: https://www.amazon.co.uk/Wellbeing-Economy-SuccessWithout-Growth-ebook/dp/B071NVRLQJ/ref=sr_1_1?ie=UTF8\&qid=1543857397\&sr=8$1 \&$ keywords=Fioramonti+A+wellbeing+economy.

Floud, S. et al. (2016) 'The role of health-related behavioural factors in accounting for inequalities in coronary heart disease risk by education and area deprivation: prospective study of 1.2 million UK women', BMC Medicine. BMC Medicine, 14(1), p. 145. doi: 10.1186/s12916-016-0687-2.

Frank, L. D. and Engelke, P. (2005) 'Multiple Impacts of the Built Environment on Public Health: Walkable Places and the Exposure to Air Pollution', International Regional Science Review, 28(2), pp. 193-216. doi: 10.1177/0160017604273853.

Gale, C. R. et al. (2011) 'Neighbourhood environment and positive mental health in older people: The Hertfordshire Cohort Study', Health \& Place. Pergamon, 17(4), pp. 867-874. doi: 10.1016/J.HEALTHPLACE.2011.05.003.

Gao, J. et al. (2017) 'Relationships between neighborhood attributes and subjective well-being among the Chinese elderly: Data from Shanghai', BioScience Trends, 11(5), pp. 516-523. doi: 10.5582/bst.2017.01170. 
Gao, M., Ahern, J. and Koshland, C. P. (2016) 'Perceived built environment and health-related quality of life in four types of neighborhoods in Xi' an, China', Health and Place. Elsevier, 39, pp. 110-115. doi: 10.1016/j.healthplace.2016.03.008.

Gardner, P. J. (2011) 'Natural neighborhood networks - Important social networks in the lives of older adults aging in place', Journal of Aging Studies. JAI, 25(3), pp. 263-271. doi: 10.1016/J.JAGING.2011.03.007.

Garnett, S. P. et al. (2016) 'Trends in the prevalence of morbid and severe obesity in Australian children aged 7-15 years, 1985-2012', PLOS ONE. doi: 10.1371/journal.pone.0154879.

Gauvin, L. et al. (2012) 'Living in a well-serviced urban area is associated with maintenance of frequent walking among seniors in the VoisiNuAge study', Journals of Gerontology - Series B Psychological Sciences and Social Sciences, 67 B(1), pp. 76-88. doi: 10.1093/geronb/gbr134.

Giehl, M. W. C. et al. (2012) 'Physical activity and environment perception among older adults: A population study in Florianópolis, Brazil', Revista de Saude Publica, 46(3), pp. 516-525. doi: 10.1590/S0034-89102012005000026.

Giles-Corti, B. et al. (2016) 'Urban design, transport, and health 1 City planning and population health: a global challenge', Lancet, 388, pp. 2912-24. doi: 10.1016/S0140-6736(16)30066-6.

Giraldez-Garcia, C. et al. (2013) 'Individual's perspective of local community environment and health indicators in older adults', Geriatrics \& Gerontology International, 13(1), pp. 130-138. doi: 10.1111/j.1447-0594.2012.00872.x.

Gong, Y. et al. (2016) 'A systematic review of the relationship between objective measurements of the urban environment and psychological distress', Environment International, 96, pp. 48-57. doi: 10.1016/j.envint.2016.08.019.

Grant, M. et al. (2017) 'Cities and health: an evolving global conversation', Cities \& Health. Routledge, 8834, pp. 1-9. doi: 10.1080/23748834.2017.1316025.

Hayward, E. et al. (2015) 'Linking social and built environmental factors to the health of public housing residents: A focus group study', BMC Public Health, 15(1), pp. 1-8. doi: 10.1186/s12889015-1710-9.

Heron, L. et al. (2019) 'Direct healthcare costs of sedentary behaviour in the UK', Journal of Epidemiology and Community Health, p. jech-2018-211758. doi: 10.1136/jech-2018-211758.

Huong, N. T. et al. (2012) 'Exploring quality of life among the elderly in Hai Duong province, Vietnam: a rural-urban dialogue.', Global health action, 5, pp. 1-12. doi: 10.3402/gha.v5i0.18874. 
Iacobucci, G. (2018) 'Medical model of care needs updating, say experts', Bmj, 360(March), p. k1034. doi: 10.1136/bmj.k1034.

Joffe, Helene and Yardley, Lucy (2004) 'Research methods for clinical and health psychology', in Joffe, $\mathrm{H}$ and Yardley, L (eds) Content and thematic analysis. London: Sage, pp. 56-68.

Jones, R. et al. (2014) 'The relative influence of neighbourhood incivilities, cognitive social capital, club membership and individual characteristics on positive mental health', Health \& Place.

Pergamon, 28, pp. 187-193. doi: 10.1016/J.HEALTHPLACE.2014.04.006.

Kaplan, S. (1987) 'Aesthetics, affect, and cognition:Environmental Preference from an Evolutionary Perspective', Environment and Behavior, 19(1), pp. 3-32. doi: 10.1177/0013916587191001.

Kearns, A. et al. (2015) “"Lonesome Town”? Is loneliness associated with the residential environment, including housing and neighborhood factors?', Journal of Community Psychology, 43(7), pp. 849-867. doi: 10.1002/jcop.21711.

Kent, J. L., Ma, L. and Mulley, C. (2017) 'The objective and perceived built environment: What matters for happiness?', Cities \& Health. Routledge, 1(1), pp. 59-71. doi: 10.1080/23748834.2017.1371456.

Kerr, J., Rosenberg, D. and Frank, L. (2012) 'The Role of the Built Environment in Healthy Aging: Community Design, Physical Activity, and Health among Older Adults', Journal of Planning Literature, 27(1), pp. 43-60. doi: 10.1177/0885412211415283.

Kolbe-Alexander, T. L. et al. (2015) 'The relationship between the built environment and habitual levels of physical activity in South African older adults: a pilot study.', BMC public health. BioMed Central, 15(1), p. 518. doi: 10.1186/s12889-015-1853-8.

Koohsari, M. J. et al. (2015) 'Public open space, physical activity, urban design and public health: Concepts, methods and research agenda', Health and Place. Elsevier, 33, pp. 75-82. doi: 10.1016/j.healthplace.2015.02.009.

Koohsari, M. J., Badland, H. and Giles-Corti, B. (2013) '(Re)Designing the built environment to support physical activity: Bringing public health back into urban design and planning', Cities, 35, pp. 294-298. doi: 10.1016/j.cities.2013.07.001.

Lakerveld, J. et al. (2015) 'Obesity-related behaviours and BMI in five urban regions across Europe: sampling design and results from the SPOTLIGHT cross-sectional survey', BMJ Open, 5(10), p. e008505. doi: 10.1136/bmjopen-2015-008505.

Lawton, MP and Nahemow, L. (1973) 'Ecology and the aging process', in Eisdorfer, C. and Lawton, 
M (eds) Psychology of adult Development and Aging. Washington, DC: American Psychological Association, pp. 619-674. doi: http://dx.doi.org/10.1037/10044-000.

Lee, I. M. et al. (2012) 'Effect of physical inactivity on major non-communicable diseases worldwide: An analysis of burden of disease and life expectancy', The Lancet. Elsevier Ltd, 380(9838), pp. 219229. doi: 10.1016/S0140-6736(12)61031-9.

Lemes de Oliveira, F. (2017) Green wedge urbanism : history, theory and contemporary practice. London: Bloomsbury.

Levasseur, M. et al. (2016) 'How to Find Lessons from the Public Health Literature: Example of a Scoping Study Protocol on the Neighborhood Environment', International Journal of Preventive Medicine, 7, p. 83. doi: https://dx.doi.org/10.4103/2008-7802.184311.

Lewis, S. (2017) 'Dementia and Town Planning: Creating better environments for people living with dementia', Royal Town Planning Institute. London: Royal Town Planning Institute, pp. 1-16. Available at: http://rtpi.org.uk/knowledge/practice/dementia-and-town-planning/ (Accessed: 18 May 2017).

Lo, B. K. et al. (2017) 'Environmental influences on physical activity among rural adults in Montana, United States: Views from built environment audits, resident focus groups, and key informant interviews', International Journal of Environmental Research and Public Health, 14(10). doi: 10.3390/ijerph14101173.

Lynch, K. (1960) Image of the City, Image of the City. Cambridge: Harvard University Press. doi: $10.2307 / 427643$.

Maas, J. et al. (2009) 'Social contacts as a possible mechanism behind the relation between green space and health', Health and Place. Elsevier Ltd, 15, pp. 586-595. Available at: http://10.0.3.248/j.healthplace.2008.09.006.

Macintyre, S., Maciver, S. and Sooman, A. (1993) 'Area, Class and Health: Should we be Focusing on Places or People?', Journal of Social Policy. Cambridge University Press, 22(02), pp. 213-234. doi: $10.1017 /$ S0047279400019310.

Mahmood, A. et al. (2012) 'A photovoice documentation of the role of neighborhood physical and social environments in older adults' physical activity in two metropolitan areas in North America', Social Science and Medicine. doi: 10.1016/j.socscimed.2011.12.039.

Malecki, K. C. et al. (2014) 'The Wisconsin Assessment of the Social and Built Environment (WASABE): a multi-dimensional objective audit instrument for examining neighborhood effects on health.', BMC public health, 14, p. 1165. doi: 10.1186/1471-2458-14-1165. 
Marmot, M. (2015) 'The health gap: the challenge of an unequal world', The Lancet. London: Bloomsbury, 386(10011), pp. 2442-2444. doi: 10.1016/S0140-6736(15)00150-6.

Mathis, A., Rooks, R. and Kruger, D. (2015) 'Improving the neighborhood environment for urban older adults: Social context and self-rated health', International Journal of Environmental Research and Public Health, 13(1), pp. 1-13. doi: 10.3390/ijerph13010003.

Milne, G. (2015) 'The Evolutionary Determinants of Health Programme : Urban Living in the 21 st Century from a Human Evolutionary Perspective', Archaelogy International, (18), pp. 84-96.

Milne, G. (2017) 'A Conceptual Approach to Urban Wellbeing from a Human Evolution Perspective', Preprints. London, 372(December), pp. 1655-1660. doi: 10.20944/preprints201712.0041.v1.

Mitchell, L. and Burton, E. (2010) 'Designing dementia-friendly neighbourhoods: Helping people with dementia to get out and about', Journal of Integrated Care, 18(6), pp. 11-18. doi:

10.5042/jic.2010.0647.

Mitchell, R. and Popham, F. (2008) 'Effect of exposure to natural environment on health inequalities: an observational population study', Lancet, 372, pp. 1655-1660.

Nabielek, K., Hamers, D. and Evers, D. (2016) 'Cities in the Netherlands: Facts and figures on cities and urban areas'. The Hague: PBLNetherlands Environmental Agency, pp. 1-18.

Nahemow, L. and Lawton, M. P. (1973) 'Toward an ecological theory of adaptation and aging', in Preiser, W. (ed.) Environmental Design Research. Stroudsburg Pennsylvania: Dowden, Hutchison \& Ross, pp. 24-32.

NHS (2016) Health and high quality care for all, now and for future generations. Healthy New Towns. Available at: https://www.england.nhs.uk/ourwork/innovation/healthy-newtowns/\#demonstrator (Accessed: 14 November 2016).

NHS England (2018) How old is an older person?, National Health Service. Available at: https://www.england.nhs.uk/ourwork/clinical-policy/older-people/improving-care-for-older-people/ (Accessed: 26 November 2018).

NHS Portsmouth Clinical Commissioning Group (2016) Joint Strategic Needs Assessment Annual Summary. Portsmouth.

NICE (2013) The social care guidance manual, National Institute for Health and Care Excellence. NICE. Available at: https://www.nice.org.uk/process/pmg10/chapter/appendix-b-methodologychecklist-systematic-reviews-and-meta-analyses (Accessed: 1 July 2017).

O’Leary, D. F. et al. (2017) 'Using rapid reviews: an example from a study conducted to inform 
policy-making', Journal of Advanced Nursing, 73(3), pp. 742-752. doi: 10.1111/jan.13231.

OECD (2017) Preventing Ageing Unequally. Paris: OECD Publishing. doi: 10.1787/9789264279087en.

Ory, M. G. et al. (2016) 'Social and environmental predictors of walking among older adults', BMC Geriatrics. BMC Geriatrics, 16(1). doi: 10.1186/s12877-016-0327-x.

Ottoni, C. A. et al. (2016) “"Benches become like porches”: Built and social environment influences on older adults' experiences of mobility and well-being', Social Science \& Medicine. Pergamon, 169, pp. 33-41. doi: 10.1016/J.SOCSCIMED.2016.08.044.

PHE (2017) Wider Determinants of Health, Public Health England. Available at: https://fingertips.phe.org.uk/profile/wider-determinants (Accessed: 15 June 2017).

Pineo, H. et al. (2018) 'Promoting a healthy cities agenda through indicators: development of a global urban environment and health index', Cities \& Health. Routledge, 2(1), pp. 1-19. doi: 10.1080/23748834.2018.1429180.

Pineo, H., Chang, M. and Pinto, A. (2015) 'P15 . Using the planning process to shape healthy environments'. London: Building Research Establishment, pp. 1-29.

Public Participation Team (2017) 'Patient and Public Participation Policy'. Leeds: NHS, pp. 1-16. Available at: https://www.england.nhs.uk/wp-content/uploads/2017/04/ppp-policy.pdf (Accessed: 22 June 2018).

Rantakokko, M. et al. (2012) 'Perceived barriers in the outdoor environment and development of walking difficulties in older people', Age and Ageing. Oxford University Press, 41(1), pp. 118-121. doi: 10.1093/ageing/afr136.

Renalds, A., Smith, T. H. and Hale, P. J. (2010) 'A systematic Review of Built Environment and Health.pdf', Fam Community Health, 33(1), pp. 68-78.

Rietveld, E. (2010) 'ALLEDAAGS HANDELEN ZONDER NA TE DENKEN', Algemeen Nederlands Tijdschrift voor Wijsbegeerte, 102, pp. 245-253. Available at: https://www.academia.edu/26979139/Bekwaam_handelen_zonder_reflectie.

Rioux, L. and Werner, C. (2011) 'Residential satisfaction among aging people living in place', Journal of Environmental Psychology. Academic Press, 31(2), pp. 158-169. doi: 10.1016/J.JENVP.2010.12.001.

Roe, J. J., Aspinall, P. A. and Thompson, C. W. (2017) 'Coping with stress in deprived urban neighborhoods: What is the role of green space according to life stage?', Frontiers in Psychology, 
8(OCT), pp. 1-17. doi: 10.3389/fpsyg.2017.01760.

Sallis, J. F., Cerin, E., et al. (2016) 'Physical activity in relation to urban environments in 14 cities worldwide: a cross-sectional study', The Lancet, 387(10034), pp. 2207-2217. doi: 10.1016/S01406736(15)01284-2.

Sallis, J. F., Bull, F., et al. (2016) 'Urban design, transport and health 3 Use of science to guide city planning policy and practice: how to achieve healthy and sustainable future cities', The Lancet, 388(10062), pp. 2936-2947. doi: 10.1016/S0140-6736(16)30068-X.

Saunders, L. and Transport for London (2018) 'Prioritising health in planning'. London: Transport for London.

Scott, S. B., Jackson, B. R. and Bergeman, C. S. (2011) 'What contributes to perceived stress in later life? A recursive partitioning approach', Psychology and Aging, 26(4), pp. 830-843. doi: 10.1037/a0023180.

Smith, B. et al. (2018) 'Physical activity for general health benefits in disabled adults: Summary of a rapid evidence review for the UK Chief Medical Officers' update of the physical activity guidelines'. London, UK: Public Health England, pp. 1-31.

Strobl, R. et al. (2016) 'Relevance of community structures and neighbourhood characteristics for participation of older adults: a qualitative study', Quality of Life Research, 25(1), pp. 143-152. doi: 10.1007/s11136-015-1049-9.

Stronegger, W. J., Titze, S. and Oja, P. (2010) 'Perceived characteristics of the neighborhood and its association with physical activity behavior and self-rated health', Health and Place. Elsevier, 16(4), pp. 736-743. doi: 10.1016/j.healthplace.2010.03.005.

Tallis, M. J. et al. (2015) 'The impacts of green infrastructure on air quality and temperature', in Sinnett, D., Smith, N., and Burgess, S. (eds) Handbook on Green Infrastructure. Cheltenham: Edward Elgar Publishing Ltd, pp. 30-49. doi: 10.4337/9781783474004.00008.

Taylor, J., Twigg, L. and Mohan, J. (2015) 'Understanding neighbourhood perceptions of alcoholrelated anti-social behaviour', Urban Studies, 52(12), pp. 2186-2202. doi:

$10.1177 / 0042098014543031$.

Tiernan, C. et al. (2013) 'Community Engagement: An Essential Component of Well-Being in Older African-American Adults', The International Journal of Aging and Human Development, 77(3), pp. 233-257. doi: 10.2190/AG.77.3.d.

Tilley, S. et al. (2017) ‘Older people's experiences of mobility and mood in an urban environment: A 
mixed methods approach using electroencephalography (EEG) and interviews', International Journal of Environmental Research and Public Health, 14(2). doi: 10.3390/ijerph14020151.

Tiraphat, S. et al. (2017) 'The role of age-friendly environments on quality of life among thai older adults', International Journal of Environmental Research and Public Health, 14(3). doi: 10.3390/ijerph14030282.

Toma, A., Hamer, M. and Shankar, A. (2015) 'Associations between neighborhood perceptions and mental well-being among older adults', Health \& Place. Pergamon, 34, pp. 46-53. doi: 10.1016/J.HEALTHPLACE.2015.03.014.

Townshend, T. and Lake, A. (2017) 'Townshend T , Lake A . Obesogenic Environments: current evidence of the built and food environments', Perspectives in Public Health, 137(1), pp. 38-44.

Turrell, G. et al. (2013) 'Can the built environment reduce health inequalities? A study of neighbourhood socioeconomic disadvantage and walking for transport', Health and Place. Elsevier, 19(1), pp. 89-98. doi: 10.1016/j.healthplace.2012.10.008.

United Nations (2017) Global Issues: Ageing, United Nations. Available at:

http://www.un.org/en/sections/issues-depth/ageing/ (Accessed: 26 November 2018).

van Dijk, L. and Rietveld, E. (2017) 'Foregrounding sociomaterial practice in our understanding of affordances: The skilled intentionality framework', Frontiers in Psychology, 7(JAN), pp. 1-12. doi: 10.3389/fpsyg.2016.01969.

Vine, D., Buys, L. and Aird, R. (2012) 'Experiences of Neighbourhood Walkability Among Older Australians Living in High Density Inner-City Areas', Planning Theory \& Practice, 13(3), pp. 421444. Available at: http://www.tandfonline.com/doi/pdf/10.1080/14649357.2012.696675.

Völker, S. and Kistemann, T. (2013) “'I'm always entirely happy when I'm here!” Urban blue enhancing human health and well-being in Cologne and Düsseldorf, Germany', Social Science and Medicine. Elsevier Ltd, 91, pp. 141-152. doi: 10.1016/j.socscimed.2013.04.016.

Ward Thompson, C. et al. (2014) 'Do changes to the local street environment alter behaviour and quality of life of older adults? the "DIY Streets" intervention', British Journal of Sports Medicine, 48(13), pp. 1059-1065. doi: 10.1136/bjsports-2012-091718.

Ward Thompson, C., Aspinall, P., et al. (2016) 'Mitigating stress and supporting health in deprived urban communities: The importance of green space and the social environment', International Journal of Environmental Research and Public Health, 13(4). doi: 10.3390/ijerph13040440.

Ward Thompson, C., Silveirinha de Oliveira, E., et al. (2016) 'Urban green spaces and health. A 
review of the evidence.' Copenhagen: WHO, pp. 1-92.

WHO (2007) Global Age-friendly Cities: A Guide, Ageing and Life Course, Family and Community Health. Geneva. WHO. doi:

http://whqlibdoc.who.int/publications/2007/9789241547307_eng.pdf?ua=1.

WHO (2015) Measuring the Age-Friendliness of Cities: a guide to using core indicators.

Geneva.WHO. Available at:

http://apps.who.int/iris/bitstream/handle/10665/203830/9789241509695_eng.pdf?sequence=1.

WHO Regional Office Europe (2017) Age-friendly environments in Europe. A handbook of domains for policy action. Copenhagen. WHO Available at:

http://www.euro.who.int/_data/assets/pdf_file/0011/359543/AFEE-handbook.PDF?ua=1\%0Abajado: 10-01-2017.

Wilkinson, R. G. and Pickett, K. (2010) The spirit level : why equality is better for everyone. London : Penguin.

Wong, M., Yu, R. and Woo, J. (2017) 'Effects of perceived neighbourhood environments on selfrated health among community-dwelling older Chinese', International Journal of Environmental Research and Public Health, 14(6), pp. 1-17. doi: 10.3390/ijerph14060614.

Yahaya, N. et al. (2012) 'Impact of Housing Environment and Neighbourhood Safety Towards Perceived Quality of Life Among Older Persons', Indian Journal of Gerontology, 26(2), pp. 227-241.

Yu, R. et al. (2017) 'Associations between perceived neighborhood walkability and walking time, wellbeing, and loneliness in community-dwelling older Chinese people in Hong Kong', International Journal of Environmental Research and Public Health, 14(10), pp. 1-15. doi: 10.3390/ijerph14101199.

Zandieh, R. et al. (2017) 'Do inequalities in neighborhood walkability drive disparities in older adults' outdoor walking?', International Journal of Environmental Research and Public Health, 14(7). doi: 10.3390/ijerph14070740.

Zapata-Diomedi, B., Herrera, A. M. M. and Veerman, J. L. (2016) 'The effects of built environment attributes on physical activity-related health and health care costs outcomes in Australia', Health \& Place, 42, pp. 19-29. doi: 10.1016/j.healthplace.2016.08.010.

Zuniga-Teran, A. A. et al. (2017) 'Neighborhood design, physical activity, and wellbeing: Applying the walkability model', International Journal of Environmental Research and Public Health, 14(1). doi: 10.3390/ijerph14010076. 
